\title{
Application of Markov chain to wind speed in Northern Peninsular Malaysia
}

\author{
Husna Hasan ${ }^{1 *}$, Affaf Mohamad ${ }^{2}$, Nur Hanim Mohd Salleh ${ }^{3}$ \\ ${ }^{1,3}$ University of Science, Malaysia, George Town, Malaysia \\ ${ }^{2}$ Kolej Matrikulasi Kedah, Changlun, Malaysia
}

\author{
Index Terms \\ Markov Chain \\ Wind Speed \\ Trend \\ Transition Probability Matrix \\ Beaufort Scale
}

Received: 24 October 2016

Accepted: 21 April 2017

Published: 30 June 2017

\begin{abstract}
This study applied the Markov chain model on the daily average wind speed data recorded at the meteorological stations in northern Peninsular Malaysia. This study aims to investigate the trend of wind speed by obtaining the transition probability matrix and the stationary distribution vector for each of the stations. The five states of wind speed based on the Beaufort scale ranging from the scale Beaufort 0 up to Beaufort 4 were defined. The stationary distribution vectors obtained revealed that Kota Bharu, Kuala Terengganu and Bayan Lepas demonstrated the highest proportion of daily average wind speed occurring in the scale of Beaufort 2 with the proportion of $69.27 \%, 63.62 \%$ and $61.89 \%$ respectively. Meanwhile, Alor Setar and Chuping showed the highest proportion of daily average wind speed occurring in the scale of Beaufort 1 with the proportion of $54.52 \%$ and $72.29 \%$ respectively. Furthermore, Kota Bharu and Kuala Terengganu also showed $9.30 \%$ and $7.13 \%$ proportion of daily average wind speed occurring more than 3.3 meter per second (Beaufort 3 and above) while Bayan Lepas station only demonstrates approximately $3.31 \%$ of the category. The least proportion displayed for this category is Alor Setar with $0.6 \%$ and followed by Chuping with $1.98 \%$.
\end{abstract}

\section{INTRODUCTION}

Around the world, people give a lot of attention to the renewable energy issue. Renewable energy such as wind energy, biomass, solar energy and hydropower are discovered world widely [1, 2]. As an alternative energy, renewable energy is the most convenient energy to be utilized due to its advantages of never ending and long lasting [3]. In Malaysia, the wind energy has not only been used for navigation and agriculture but also become an alternative energy for generating electricity.

An article [4] revealed that the Malaysian Electricity Supply Industries Trust Account and the Ministry of Science, Technology and Innovation had granted about RM 3 million to Sustainable Energy Development Authority Malaysia (SEDA) and University Malaysia Terengganu (UMT) for a two-year research on wind at 11 sites in Malaysia. The data on wind are recorded and analysed to develop wind map and generate new energy source. Malaysia is divided into two distinct parts which are Peninsular Malaysia and the East Malaysian provinces of Sabah and Sarawak.

This country experiences two monsoons named southwest monsoon (May to September) and northeast monsoon (November to March). The wind speed during the northeast monsoon is usually higher than the southwest monsoon.

The reading of wind speed is often below $7 \mathrm{~ms}-1$ during southwest monsoon but the wind speed reading could reach up to $15 \mathrm{~ms}-1$ during northeast monsoon [5]. Based on the recent studies conducted by many researchers, the annual mean wind speed in Malaysia ranges from 2.0 - 5.0 ms-1 [6].

Most of the studies that had been carried out were interested in modelling the wind speed for the purpose of

\footnotetext{
* Corresponding author: Husna Hasan

†Email: husnahasan@usm.my
} 
forecasting the future trend accurately. However, the speed of the wind and how frequent that it happened had rarely been discussed in detail. The speed of the wind is important to take into account especially if it is to be considered as potential wind energy resource. This is because wind speed is known to be the most significant parameter in generating wind energy.

To understand the trend of wind speed at five selected states in Peninsular Malaysia, this study is conducted by applying Markov Chain model onto wind speed data and the computation is done using $\mathrm{R}$ programming software. This Markov Chain approach was also applied by [7] and [8] for investigating the maximum temperature trend for thermal comfort in Malaysia.

\section{BACKGROUND OF STUDY}

Markov chain is known as a stochastic process that has been applied in various studies. In the area of branching process, it was initially used to predict the survival and extinction of royal families. Since then, the used of Markov chain model has been extended in other areas of studies. [9] used Markov chain model and came out with a transition probability matrix to represent the time series of ten years' hourly average wind speed data which were obtained at Tangiers, Morocco.

Result showed that the limiting behavior agreed with the histogram of the observed data. The transition probability matrix was also used to simulate wind speed data by generating synthetic wind speed series using a transformed variable. The statistical characteristics of the generated wind speed data were proven faithful to the observed data in the study.

[10] incorporated seasonal data by using Markov chain model in their study. The hourly average wind speed datasets obtained from the operational meteorological towers at National Wind Te chnology Center, Colorado (one year data) and Süpürgelik region of Yalova, Turkey (9 months' data) were divided into 4 seasons namely winter, spring, summer and autumn.

The first month of each season was used to form the Markov chain model which was then used to generate synthetic wind data, to be compared with the data for the rest of the month in the season. Results showed that one month of observed data was sufficient to generate synthesized wind speed series for the related season accurately. This outcome also implies that Markov chain model can be used to complete missing data.

\section{DATA DESCRIPTION}

\section{A. Data}

The data used in this study were obtained from the Malaysian Meteorological Department. They comprised of recorded wind speed which were documented as a twenty four hours' mean value in meter per second (ms-1). The period of data is twenty years observed from 1st January 1994 to 31st December 2013.

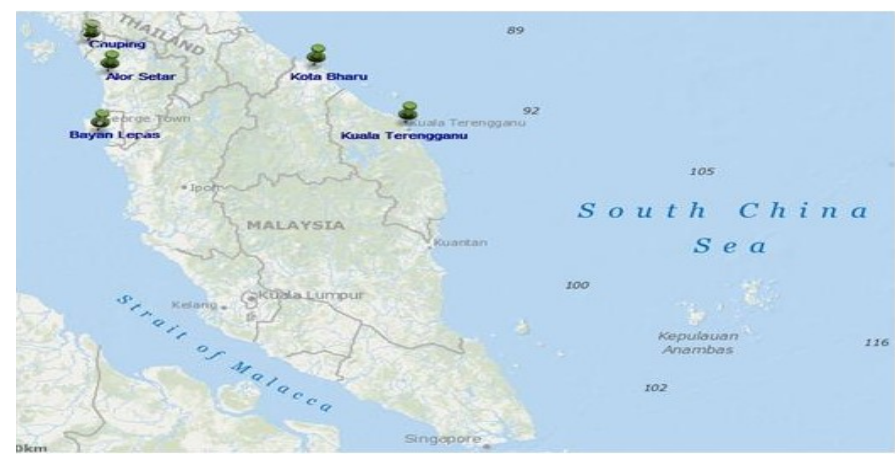

Fig. 1. Location of meteorological stations

The study investigates the wind speed data recorded at five meteorological stations which are located at the northern part of Peninsular Malaysia (Figure 1). The geographical backgrounds of the selected stations are listed in Table 1. Alor Setar, Bayan Lepas and Chuping are located at northwest region while Kota Bharu and Kula Terengganu are located at eastern region of Peninsular Malaysia. Both regions are separated by the Titiwangsa Mountains.

TABLE 1

LIST OF METEOROLOGICAL STATIONS INCLUDED IN THE STUDY AND THEIR DETAILS

\begin{tabular}{cccc}
\hline \hline Meteorological Station & Latitude & Longitude & Height above Mean Sea Level (Meter) \\
\hline Alor Setar & $6^{\circ} 12^{\prime} \mathrm{N}$ & $100^{\circ} 24^{\prime} \mathrm{E}$ & 3.9 \\
Bayan Lepas & $5^{\circ} 18^{\prime} \mathrm{N}$ & $100^{\circ} 16^{\prime} \mathrm{E}$ & 2.5 \\
Chuping & $6^{\circ} 29^{\prime} \mathrm{N}$ & $100^{\circ} 16^{\prime} \mathrm{E}$ & 21.7 \\
Kota Bharu & $6^{\circ} 10^{\prime} \mathrm{N}$ & $102^{\circ} 18^{\prime} \mathrm{E}$ & 4.4 \\
Kuala Terengganu & $5^{\circ} 23^{\prime} \mathrm{N}$ & $103^{\circ} 06^{\prime} \mathrm{E}$ & 5.2 \\
\hline \hline
\end{tabular}

\section{B. Beaufort Scale}

The data obtained from the Malaysian Meteorological Department are raw data on daily average wind speed in ms-1. Therefore, there must be a certain scale to categorize the wind speed into a finite number of states so that it is ap- 
plicable to form a Markov chain model. Beaufort scale had been chosen to form the states of wind speed in this study. The full range of levels in Beaufort scale used by the [11] was referred and fit accordingly based on the data which led to only six scales. Table 2 lists the descriptive term for each scale together with the range of wind speed it represents in meter per second (ms-1). To date, the Beaufort scale is still used by the World Meteorological Organization (formerly known as International Meteorological Organization) to indicate wind speed in its operational use especially for the marines and sailors. [12] highlighted that the meaningfulness and simplicity of each scale in Beaufort scale make the scale a useful tool to predict and observe the weather.

TABLE 2

BEAUFORT SCALE AND ITS DETAILS

\begin{tabular}{ccc}
\hline \hline Beaufort Scale & Descriptive Term & Range of Wind Speed (ms-1) \\
\hline 0 & Calm & $0-0.2$ \\
1 & Light air & $0.3-1.5$ \\
2 & Light breeze & $1.6-3.3$ \\
3 & Gentle breeze & $3.4-5.4$ \\
4 & Moderate breeze & $5.5-7.9$ \\
5 & Fresh breeze & $8.0-10.7$ \\
\hline
\end{tabular}

\section{METHODOLOGY}

\section{A. Markov Chain Model}

[13] defined Markov chain as a discrete stochastic process where the conditional distribution of any future state given its past and present states depends only on the present state. This means that it is independent of its past states. [14] explained that the dependence structure among the random variables is the issue addressed by the Markovian property. It is said that in generating the sequence $X_{0}$, $\mathrm{X}_{1}, \ldots$, the next state $\mathrm{X}_{t+1}$ depends only on the current state of $X_{t}$ and independent of the past values of $X_{0}, X_{1}, \ldots X_{t-1}$. A sequential process $\mathrm{X}_{0}, \mathrm{X}_{1}, \mathrm{X}_{2} \ldots$ satisfies Markovian property if

$P\left\{X_{t+1}=i_{t=1} \mid X_{t}=i_{t}, X_{t-1}=i_{t-1}, \ldots, X_{1}=i_{1}, X_{0}=i_{0}\right\}$ $=P\left\{X_{t+1}=i_{t=1} \mid X_{t}=i_{t}\right\}$

If $X_{t}=i$, it means that the process is in state $i$ at time $t$. There is a fixed probability that it will move into state $j$ at time $t+1$ and this probability is denoted by $p_{i j}$. This value is a conditional probability of $j$ given $i$ and is called the transition probability of state $i$ into state.

$$
p_{i j}=P\left\{X_{t+1}=j \mid X_{t}=i\right\}
$$

\section{B. Transition Probability Matrix}

The value of $p_{i j}$ and the transition probability matrix for a first order Markov chain model can be determined and arranged as follows:

$$
\mathrm{P}=\left[\begin{array}{cccc}
p_{11} & p_{12} & p_{13} \cdots & p_{1 m} \\
p_{21} & p_{22} & p_{23} \ldots & p_{2 m} \\
\vdots & \vdots & \vdots & \vdots \\
p_{m 1} & p_{m 2} & p_{m 3} \cdots & p_{m m}
\end{array}\right]
$$

\section{Matrix Multiplication and Iteration}

[13] further defined the transition probability matrix $P^{(\mathrm{n})}$ as the $n$ state transition probability matrix where each element $p_{i j}^{n}$ represents the probability that it was initially in state $i$ and moved into state $j$ after $n$ additional transitions. The conditional probability of $p_{i j}^{n}$ is defined as follows:

$$
p_{i j}^{n}=P\left\{X_{t+n}=j \mid X_{t}=i\right\}
$$

The method to obtain the transition probability matrix $P^{(\mathrm{n})}$ can be derived by using the Chapman-Kolmogorov equation. The Chapman-Kolmogorov equation supports that the matrix $P^{(\mathrm{n}+\mathrm{m})}$ can be obtained by multiplying the matrix $P^{(\mathrm{n})}$ with $P^{(\mathrm{n})}$.

$$
p_{i j}^{n}+m=\sum_{k-0}^{\infty} p_{i j}^{n}-p_{i j}^{m}
$$

Based on the result above, [13] determined the transition probability matrix $P^{(\mathrm{n})}$ by induction as the following equation. The equation implies that $P^{(\mathrm{n})}$ can be determined by multiplying the matrix P by itself $n$ times.

$$
P^{(\mathrm{n}+\mathrm{m})}=P^{(\mathrm{n})} P^{(\mathrm{m})}
$$

[15] xplained that as $n$ tends to infinity, the stochastic matrix $P^{(\mathrm{n})}$ converges to a matrix where its row possesses the same probability vector. This matrix is the limiting probability for the Markov chain model as it is an invariant probability vector. However, it is only applicable for an irreducible Markov chain. By using the basic limit theorem, the stationary distribution can be determined by running the chain for a long time until the same values of $p_{i j}^{n}$ occur for all conditioned state $i$ in the transition probability matrix $P^{(\mathrm{n})}$. 


\section{RESULTS AND DISCUSSION}

\section{A. Data Classification}

By assigning the data in this study to its Beaufort scale, the categories of the daily average wind speed for each of the stations involved are summarized in Table 3. The result shows that Alor Setar, Bayan Lepas and Chuping each has 4 categories of wind speed while Kota Bharu and Kuala Terengganu have 6. However, since there is only one observation recorded as Beaufort 5 for Kota Bharu and Kuala Terengganu stations and these values are close to the lower limit in the scale, these observations are treated as wind speed category Beaufort 4.

TABLE 3

NUMBER OF DAYS TALLIED CORRESPONDS TO THE BEAUFORT SCALE FOR EACH OF THE STATIONS

\begin{tabular}{llllllll}
\hline \hline $\begin{array}{l}\text { Beaufort Scale } \\
\text { Station }\end{array}$ & B0 & B1 & B2 & B3 & B4 & B5 & Total \\
\hline Alor Setar & 18 & 3965 & 3247 & 46 & 0 & 0 & 7276 \\
Bayan Lepas & 1 & 2540 & 4521 & 242 & 0 & 0 & 7304 \\
Chuping & 32 & 5266 & 1839 & 146 & 0 & 0 & 7283 \\
Kota Bharu & 2 & 1438 & 4662 & 543 & 79 & 1 & 6725 \\
Kuala Terengganu & 5 & 2128 & 4641 & 463 & 62 & 1 & 7300 \\
\hline \hline
\end{tabular}

This number of categories indicates the dimension of their respective transition probability matrix. To achieve this, the transitions between two consecutive days for each category were tallied so that the transition probability matrix, $\mathrm{P}$ can be evaluated. Based on the table above, Alor Setar, Bayan Lepas and Chuping stations show that the daily average wind speed was recorded in 4 states, from Beufort 0 up to Beaufort 3.

Therefore, the Markov chain model for these stations can be modelled with a transition probability matrix. Similarly, Kota Bharu and Kuala Terengganu stations show that the daily average wind speed was recorded in 5 states, from Beufort 0 up to Beaufort 4 (one observation of Beaufort 5 was treated as Beaufort 4 for each of the stations). Hence, the Markov chain model for these stations can be modelled with a transition probability matrix.

\section{B. Transition Probability}

Figure 2 shows the resulting transition probability diagram for Alor Setar, Bayan Lepas and Chuping stations while Figure 3 illustrates the resulting transition probability diagram for Kota Bharu and Kuala Terengganu stations.
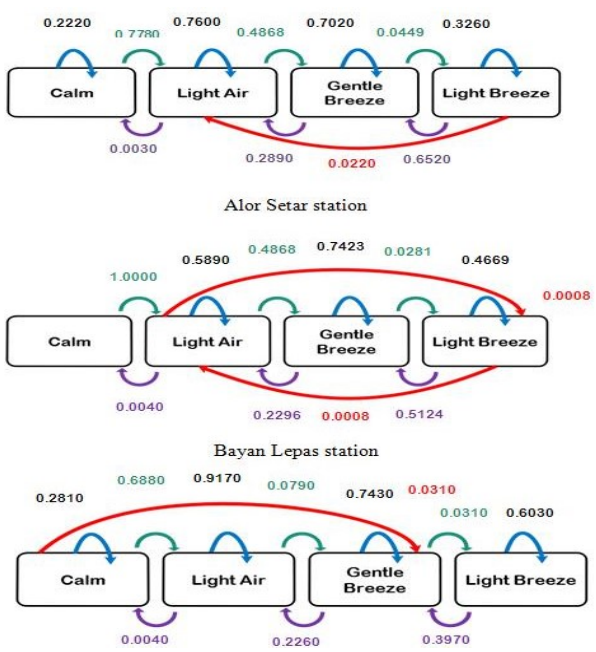

Fig. 2. Transition probability diagram for Alor Setar, Bayan Lepas and Chuping Stations

The probability values as presented in the diagrams are extracted from the transition probability matrix, $P$. Based on the diagram, it is interesting to note that one state transition probability value (Green color) for Alor Setar, Bayan Lepas and Chuping stations is increasing from the Calm towards the Light Breeze state. On the contrary, a decreasing trend of one state transition probability value (Purple color) is spotted from Light Breeze to Calm state. Nevertheless, for Kota Bharu and Kuala Terengganu stations, the one state transition probability value is rising from the Calm towards the Light Breeze state but declining from Light Breeze to Moderate Breeze state.
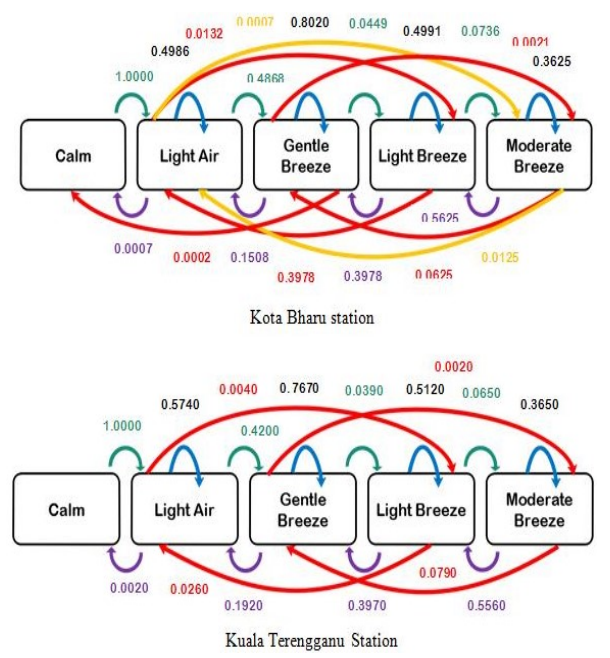

Fig. 3. Transition probability diagram for Kota Bharu and Kuala Terengganu Stations

ISSN: 2414-3103

DOI: $10.20474 /$ japs-3.2.2 


\section{Limiting State Probabilities}

The iteration of multiplication of the transition probability matrix $P$ with itself was conducted until the stationary distribution was obtained. For Alor Setar, Bayan Lepas and Chuping, Kota Bharu and Kuala Terengganu stations, the convergence of the transition probabilities can be seen at the result of $P^{(29)}, P^{(24)}, P^{(56)}, P^{(36)}$ and $P^{(32)}$ respectively. When each row of the transition probability matrix is similar, the result indicates that the limiting probabilities for the Markov chain model have been reached for each of the stations.

TABLE 4

SUMMARY OF STATIONARY DISTRIBUTIONS AT ALL THE METEOROLOGICAL STATIONS

\begin{tabular}{llllll}
\hline \hline $\begin{array}{l}\text { Limiting } \\
\text { Probabilities }\end{array}$ & B0 & B1 & B2 & B3 & B4 \\
\hline Alor Setar & 0.0021 & 0.5452 & 0.4467 & 0.0060 & 0 \\
Bayan Lepas & 0.0001 & 0.3478 & 0.6189 & 0.0331 & 0 \\
Chuping & 0.0040 & 0.7229 & 0.2533 & 0.0198 & 0 \\
Kota Bharu & 0.0003 & 0.2140 & 0.6927 & 0.0811 & 0.0119 \\
Kuala Terengganu & 0.0006 & 0.2919 & 0.6362 & 0.0629 & 0.0084 \\
\hline \hline
\end{tabular}

Table 4 and Figure 4 summarize the limiting probabilities obtained at each of the stations involved in this study. The result shows that the daily average wind speed recorded at Kuala Terengganu station shows a similar trend with Kota Bharu station. Both stations show the highest proportion of daily average wind speed occurring in the scale of Beaufort 2 and followed by Beaufort 1 and Beaufort 3 . Both stations also show that there are chances of daily average wind speed occurring in the scale of Beaufort 4 . The similarity between these two stations is parallel to their respective region.

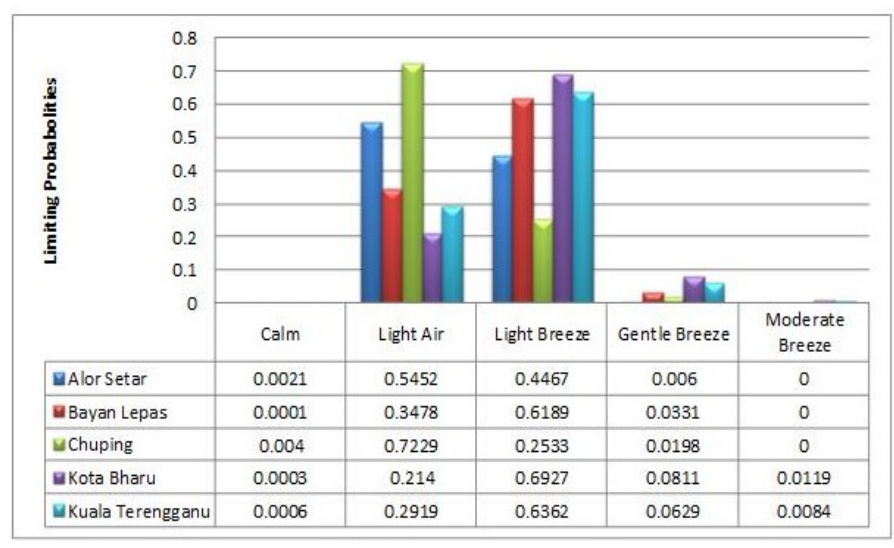

Fig. 4. Limiting probabilities graph for each state
Chuping station shows the highest proportion of daily average wind speed occurring in the scale of Beaufort 1 and Beaufort 2 compared to the other stations. These values suggested that, most of the time, Chuping has a weaker daily average wind speed compared to the other stations. Bayan Lepas station also shows the highest proportion of daily average wind speed occurring in the scale of Beaufort 2 and then followed by Beaufort 1. This trend is similar to Kota Bharu and Kuala Terengganu stations. However, the daily average wind speed is restricted up to the scale in category Beaufort 3 where the proportion of time is $3.31 \%$. Alor Setar station shows a different outcome compared to the others. Even though it shows that the daily average wind speed most frequently occurs in the scale of Beaufort 1 and followed by Beaufort 2 similar to Chuping station, the difference between the proportions is small compared to the range it shows at Chuping station.

\section{CONCLUSION}

In general the climate in Peninsular Malaysia is influenced by the northeast and southwest monsoons. Northeast monsoon begins from November each year and it ends in March the following year. On the contrary, the southwest monsoon starts in May and ends in September. In between the time, the months of April and October each year is when they are called the inter monsoon period. Kota Bharu and Kuala Terengganu stations are directly exposed to northeast monsoon while Bayan Lepas station is directly exposed to the southwest monsoon.

These three stations are also located near to the coastal area. This situation might be the cause of similar trend shown in their respective higher proportions in the higher scale of wind speed estimated for the stations. Nevertheless, there are higher wind speed scales (Beaufort 4) recorded at the Kota Bharu and Kuala Terengganu stations compared to Bayan Lepas station. This condition is different at Alor Setar and Chuping stations. They show much higher proportions in the lower scales compared to their higher scales.

Although these stations are also exposed to the southwest monsoon, the magnitude of the wind speed is relatively low compared to the other stations. $[16,17]$ described that the cut-in wind speed for most turbines is typically between 7 and 10 miles per hour. It is considered as the minimum wind speed at which the wind turbine will generate usable power. The cut-in wind speed suggested is approximately equivalent to 3.13 to 4.47 meter per second. 
The value shows that the wind speed in category Beaufort 3 and above may be exploited to be as an alternative resource of power energy. Despite that, $[18,16]$ explained that newer wind turbines are designed to operate for wind speed as low as 0.5 miles per hour which is as low as 0.22 meter per second. However, the amount of energy produced is not comparable which means that it might not be practical economically. This research is limited to only five regions located at the northern Peninsular Malaysia with twenty years' period of wind speed data. Based on the findings, Kota Bharu, Kuala Terengganu and Bayan Lepas areas are highly recommended to be explored as a potential wind energy source compared to Alor Setar and Chuping. Future study should cover wider area with longer period of data.

\section{REFERENCES}

[1] S. K. Najid, A. Zaharim, A. M. Razali, M. S. Zainol, K. Ibrahim and K. Sopian, "Analyzing the east coast Malaysia wind speed data," International Journal of Energy and Environment, vol. 3, no. 2, pp. 56-60, 2009.

[2] A. Adda, M. Abbas, W. M. Naceur and Z. Tigrine, " Con- tribution on energy consumption optimization of a brackish water solar desalination plant in Algeria," Journal of Advances in Technology and Engineering Studies, vol. 3, no. 2, pp. 37-43, 2017.

[3] A. M. Razali, M. S. Sapuan, K. Ibrahim, A. Zaharim and K. Sopian, "Mapping of annual extreme wind speed analysis from 12 stations in Peninsular Malaysia," in World Scientific and Engineering Academy and Society (WSEAS) Proceedings, Roma- nia, RO, 2010.

[4] H. Y. Leong, "Sustainable energy agency Seda mulls wind as renewable resource," 2015 [Online]. Avail- able: goo.gl/QCaQyN

[5] C. T. Boon Sung, "Possibility of electricity from wind energy in Malaysia: Some rough calculations," 2016 [Online]. Available: goo.gl/HqgVhK

[6] S. M. Lawan, W. A. W. Z. Abidin, W. Y. Chai, A. Baharun and T. Masri, "Reviewing wind speed and energy dis- $\quad$ tribution in Malaysia," European Academic Research, vol. 1, no. 8, pp. 10-19, 2013.

[7] H. Hasan, M. A. bin Che Nordin and N. H. M. Salleh,
"Modeling daily maximum temperature for thermal comfort in Northern Malaysia," Advances in Environ- mental Biology, vol. 9, no. 26, pp. 12-19, 2015.

[8] M. A. B. C. Nordin and H. Hassan, "Application of Markov chain model to daily maximum temperature for thermal comfort in Malaysia," in Applied Inverse Problems conference (AIP) Proceedings, Helsinki, FI, 2015.

[9] H. Nfaoui, H. Essiarab and A. A. M. Sayigh, "A stochastic Markov chain model for simulating wind speed time series at Tangiers, Morocco," Renew- able Energy, vol. 29, no. 8, pp. 1407-1418, 2004.

\section{DOI: $10.1016 /$ S0960-1481(03)00143-5}

[10] S. Karatepe and K. W. Corscadden, "Wind speed esti- mation: Incorporating seasonal data using Markov chain models," ISRN Renewable Energy, vol. 9, no. 16, pp. 1-9, 2013. DOI: 10.1109/MRA.2012.2229936

[11] World Meteorological Organization, "Manual on marine meteorological services," 2012 [Online]. Available: goo.gl/bGMIJG

[12] F. Singleton, "The Beaufort scale of winds-its rele- vance, and its use by sailors," Weather, vol. 63,

no. $2, \quad$ pp. 37-41,2008. DOI: 10.1002/wea.153

[13] S. M. Ross, Introduction to Probability Models. New York, NY: Academic Press, 2010.

[14] C. Rye, "Top 5 wind turbines for low speed wind condition," 2015 [Online]. Available: goo.gl/qgVLIV

[15] L. Mejlbro, "Stochastic processes 1 probability exam- ples c-8," 2015 [Online]. Available: goo.gl/qYcfJL

[16] T. Al-Shemmeri, "Wind turbines," 2015 [Online]. Available: goo.gl/FO6A46

[17] A. A. Yerzhan and M. B. Koshumbaev, "New design of low-head hydro turbine for small-scale hydropower plant," International Journal of Technology and Engi- neering Studies, vol. 2, no. 3, pp. 87-94, 2016.

DOI: $10.20469 /$ ijtes.2.40005-3

[18] J. T. Chang, "Stochastic pocesses," 2014 [Online]. Available: goo. gl/T2w2SR 